Proceedings of the International Conference on Teaching, Education and Learning Conference, Vol. 1, 2021, pp. 30-45 Copyright (C) 2021 iConferences

ISSN 2820-2155

DOI: https://doi.org/10.32789/tel.2021.1003

\title{
Teacher Professional Development through Harezmi Educational Model
}

\author{
Tuba Kıvanç Contuk ${ }^{1}$, Derin Atay $^{2}$
}

${ }^{1}$ English Language Education, Bahçeşehir University, Istanbul, Turkey, tuba.kivanc@hotmail.com ${ }^{2}$ English Language Education, Bahçeşehir University, Istanbul, Turkey, derin.atay@es.bau.edu.tr 


\title{
TEACHER PROFESSIONAL DEVELOPMENT THROUGH HAREZMI EDUCATIONAL MODEL
}

\begin{abstract}
Harezmi Educational Model, a national model first piloted in 2016, is based on the inclusion of multi-disciplines, use of computational skills in the problem-solving process, development of life skills, and using robotics, coding, and game designs in learning. Teachers interested in implementing this model are expected to attend in-service training for several weeks to gain theoretical knowledge and practical skills. The purpose of the present study is to explore how the whole process, from the training to implementation in class stages, has affected teachers' beliefs, perceptions, and attitudes regarding teaching. Sixteen teachers participated in this study. Data came from an online survey with 11 open-ended questions and online focus group interviews. In the analysis, the recurring themes were determined through content analysis, and themes that emerged at the beginning and end were compared. The results suggested that besides developing a critical eye on their own teaching, teachers improved their collaboration skills and observed an increase in their autonomy. This study is an attempt to address a gap in the field concerning this model and how this model has the potential to contribute to the professional development of teachers.
\end{abstract}

Keywords: Harezmi Educational Model, professional teacher development, teachers' perceptions, attitudes

\section{Introduction}

As the requirements of modern societies, learners today need to be creative and innovative as well as think critically, reflect on their experiences, work in collaboration, make inquiries, and develop their problem-solving skills. In line with these evolving requirements, teachers are expected to go beyond their traditional ways of teaching (in de Wal et al. 2014, Velikova, 2020). Continuing teacher professional development programs that include cognitive and emotional involvement of teachers aim to equip teachers with the skills and knowledge to boost the growth of their learners (Avalos, 2011).

In many countries, initiatives are taken to effectively provide learners with multi-disciplinary education to develop their 21st-century skills. To exemplify, in an attempt to make a reform in inflexible, overcrowded, and overly exam-focused curriculum, the Bridge 21 model, which focuses on skills such as problem solving and inquiry-based learning, was introduced in Ireland (Girvan et al. 2016). In addition, the Comprehensive School Reform Program established in the U.S. aims at constructing a national research-based educational innovation, especially with low-achieving and heterogenous student populations (Borman et al. 2003). Harezmi Educational Model (HEM) was first piloted in Turkey in 2016. This model is a national model which aims to raise students who can think multidisciplinary, find ways to avoid rote-learning, adopt scientific research methods, solve daily-life problems through their problem-solving skills and develop $21^{\text {st }}$ Century skills (Ministry of National Education [MoNE], 2018). HEM also emphasizes teacher professional development by in-service training both at the onset and during the process. In order to be included in the model, teachers have to attend onset in-service training. During the process, they are also provided with ongoing support and training. The model offers an opportunity for teacher professional development thanks to the training and its fundamental principles. The present article deals with the changes in teachers' beliefs, 
perceptions, and attitudes regarding teaching to address the issues concerning HEM and teacher professional development through this model.

\section{Background}

"Teachers learn by doing, reading, and reflecting (just as students do); by collaborating with other teachers; by looking closely at students and their work; and by sharing what they see." (DarlingHammond and McLaughlin, 2011, p. 88). Research suggests that traditional teacher development programs are not compatible with the ways that people teach (Armour, 2006, Kennedy, 2014). Transmission of knowledge type teacher development programs fail to create learning opportunities that are relevant and connected to teachers' teaching contexts and their and students' needs (Keay et al. 2019). The linear, short-term, time-limited, and disconnected programs contribute little to students' learning because they do not ensure long-term and coherent changes in teachers' practices (Keay and Lloyd, 2011). In order to produce long-term outcomes, Darling-Hammond and McLaughlin (2011) propose that teacher professional development programs should be designed as a process that is experiential, collaborative, reflective, connected to, and derived from their work and context ongoing with follow up support. These programs should be "job-embedded" and structured around teachers' work, including curriculum development with collaborative planning, lesson study, and action research (Darling-Hammond, 2017). Loucks-Hoursley et al. (1998) also suggest activities that involve collaborative interactions, one-to-one work with teachers, engagement in inquiry, an investigation into a variety of topics, and reception of support from mentors. While doing these activities, teachers have a chance to think, reflect on their teaching and share their practices with colleagues. The next session presents brief information about HEM, focusing on the teacher professional development aspect of the model.

\section{Harezmi Educational Model}

HEM is a national model that aims to raise students who can solve daily-life problems through scientific research methods and computational and algorithmic skills. It adopts a student-centered approach and is based on the inclusion of various disciplines in solving the problem. The model is named after a Turkish-Muslim scholar, Abu Abdullah Muhammed Bin Musa el-Harezmi (Harezmi as a shortened version). Harezmi is known as the father of algebra and astronomy, and the word algorithm is derived from his name el-Harezmi (MoNE, 2018).

HEM starts with a question/problem in daily life, and students try to find solutions to this question. The process lasts 32 weeks and is shaped by students and teachers together. Consequently, HEM does not have a pre-defined curriculum; instead, the process is constructed according to the problem chosen and solutions, the developmental and working stages, and the students' speed. The students do not have to develop a concrete solution because the model is process-oriented, and the process itself is considered a learning opportunity.

The model is based on five main areas: (i) inclusion of multi-disciplines, (ii) use of computational skills in the problem-solving process, (iii) development of life skills, (iv) using coding, (v) robotics and game designs in learning. The multi-disciplinary approach requires at least 3 teachers from the branches of Technology, Science and Math, and Social Sciences. The rationale behind this practice is developing a holistic approach to problem-solving rather than isolating the disciplines. Computational skills are 
related to following certain steps, abstraction, modeling, and evaluation to reach the solution of a problem; there is no need to use computers for computational skills. Development of life skills refers to abilities to find solutions to issues in daily life. Daily life skills are also important because, as Scott et al. (2018) indicated, passing a test does not help students gain a deep understanding of issues of the changing world. Lastly, in order to prepare students to solve problems that stem from unexpected situations in a world of technology; (Garay and Quintana, 2019), robotics, coding, and game designs are placed in HEM.

The model is applied as an extra-curricular activity. After a group of students from the volunteers is determined to take part, the process starts. After the classes, the students and teachers meet and work on their problems and solutions every week. Before and after the class-time, teachers are required to have a meeting for planning, evaluation, and reflection. Every two weeks, the district coordinator visits the class, observes the lessons, and attends the after-class meeting of teachers. In this meeting, teachers and the coordinator exchange their ideas; the coordinator guides teachers about their concerns and the course of events.

The application of the model with all principles requires teacher development programs specific to HEM. Consequently, teachers who want to start HEM at their schools apply for onset in-service training before the process. Due to the multi-disciplinary approach of the model, at least 3 teachers from the aforementioned branches must complete the training to start HEM at school. The in-service training, lasting for 5 days, includes the introduction and aims of the model, information about the process, the roles of teachers and students, requirements, activities, planning, forms to be filled in, and theoretical knowledge behind the model. In addition, teachers attend a variety of in-service training during the application process of the model. The training varies from technology to assessment and evaluation. From time to time, teachers are asked about the subjects that they need training in. In the literature also, it has been shown that teacher training programs that are more relevant and situated to teachers' contexts address the individual needs of teachers and students (Keay et al. 2019, Loomis et al. 2008). Table 1 shows the types and numbers of training provided in the 2019-2020 Educational Year (MoNE, 2020).

Table 1: Numbers of In-service Training offered by HEM.

\begin{tabular}{ll}
\hline Web 2.0 Tools & 649 \\
\hline Ardunio (app) & 528 \\
\hline Introduction to Coding and Robotics & 365 \\
\hline Intelligence Games & 341 \\
\hline The Use of Drama in Education & 140 \\
\hline STEM & 66 \\
\hline New Approaches to Education & 36 \\
\hline Assessment and Evaluation & 20 \\
\hline Scientific Research Methodology & 20 \\
\hline
\end{tabular}

The impetus for the study was to investigate whether becoming a HEM instructor would affect teachers' development. In line with this, the research question for the study is 'In their view, how does HEM change teachers' perspectives, beliefs, and attitudes regarding teaching?'. 


\section{Methodology}

This qualitative study is a Multiple Case Study in which a particular issue is studied from the perspectives of more than one case, which will result in better understanding and theorizing (Stake, 2005). The current study investigates the changes in beliefs, perceptions, and attitudes of teachers involved in HEM.

\section{Participants}

16 in-service teachers ( 9 females, 7 males) who work at 4 different state schools attended the study. These teachers were informed about the study in a meeting, and they volunteered to participate. The participants were chosen among the volunteers who had already completed at least one year of application of HEM after their onset training and were experienced in the model. Moreover, all of them attended at least two of the in-service training given in Table 1. To this end, all participants fulfilled the criteria to be included in the study. The teachers were from a variety of majors; class, Math, Turkish, Science, Social Sciences, Technology and Design, Special Needs Education, Physical Education, and ICT. Consequently, they brought expertise from different content areas into the classroom. Their average experience in teaching was 9.6 years, and their average age was 33.8. All teachers in the study signed consent forms indicating their voluntariness. The names given in the study are pseudonyms to protect the confidentiality of the participants.

\section{Data Collection}

Data were collected through two tools: online forms and focus group interviews. Firstly, anonymous online forms including 11 open-ended questions were sent to the participants. The questions included aspects in relation to the contributions of HEM to their professional development and classroom practices. In addition, the effects of in-service training and the whole process on their teaching were questioned in the online form. After answers were collected from all participants, the researchers worked on the areas that needed further clarification or concrete exemplification. Together with these points, focus group interviews were arranged in the groups which conducted Harezmi classes together. This grouping aimed to investigate the outcomes of this approach concerning teachers' professional development as well as group dynamics and collegiality among them. They altogether could narrate the atmosphere during class time, their meetings together for the reflection and evaluation, and feedback and support received from the coordinator. The participants were requested to elaborate on their teaching perceptions, beliefs, and practices that changed after their inclusion in the model. In addition, skills and knowledge gained during the whole process and through in-service training, the lacking points of teacher development programs and curriculum, and changing roles of students and teachers were discussed in the interviews. All the interviews were held online in Turkish and recorded by common consent. 


\section{Data Analysis}

For qualitative data, inductive analysis was adopted under the guidelines by Cresswell (2003). First, the data from the interviews, which included over 160-minute recordings, were transcribed. After comprehensive and repetitive readings, initial codes emerged in the data. The coding process was completed both for the answers from the online form and the transcriptions of the interviews. In the following round, axial coding was conducted to generate the main categories. The categories and main themes were shared with two participants from two different focus groups to increase the credibility of the findings. One of these participants possessed a sound knowledge of the model due to his academic studies and was well-aware of the coding procedures. The other participant was one of the most experienced in the application of the model. After discussion with the researchers, the participants confirmed the themes generated in the data.

\section{Results}

The qualitative thematic analysis revealed two major themes emerging in the data: changes in perceptions, beliefs, and attitudes and improvement in knowledge and skills. These two major themes included various categories. Table 2 presents the themes and categories yielded in the data.

\section{Changes in Perceptions, Beliefs, and Attitudes}

The participants indicated that being involved in HEM resulted in changes in their perceptions, beliefs, and attitudes regarding teaching. Firstly, the process-oriented approach of the model enabled them to understand the value of the process in which students came out with better learning outcomes.

Table 2: Themes and Categories

Themes Categories

\begin{tabular}{|c|c|}
\hline \multirow{6}{*}{ Changes in perceptions, beliefs, and attitudes } & Process-orientedness \\
\hline & Student-centeredness \\
\hline & Changing role of the teacher \\
\hline & Open to development \\
\hline & Using different content areas \\
\hline & Integrating daily life problems \\
\hline \multirow{5}{*}{ Improvement in knowledge and skills } & Better lesson planning \\
\hline & $\begin{array}{c}\text { Cooperation and working in } \\
\text { coordination }\end{array}$ \\
\hline & Increased interaction with students \\
\hline & Increased technological knowledge \\
\hline & Increased theoretical knowledge \\
\hline
\end{tabular}


Rather than being product-focused or trying to create something concrete, the teachers observed that students gained skills necessary for life, solving their problems, working in collaboration. Changing this mindset, the participants tried to make their lessons more process-oriented. One of the participants expressed this change as follows:

"I was very concerned about concluding the lessons and very worried whether I could give all the objectives of the lesson within the given time according to the curriculum. After Harezmi, I realized that I was pushing the students too hard. However, now I see that students can learn in a simpler process even when you do not end up with a final product."

This process-orientedness paved the way for a student-centered approach in the lessons. Studentcenteredness includes active engagement of the students and autonomous construction of knowledge by the students (Geven and Santa, 2010). In this model, students and teachers decide on the subject or a problem they want to study and construct their development plan in the process. Students regulate the process; they think about a daily life problem, its sub-problems, make research or surveys, come up with ideas for the solution or prevention of the problem. Teachers observe the process and guide students when they need help. The knowledge is not transmitted from teachers to students; rather, students construct the knowledge themselves. After the model, the participants realized that the model provided the students with more flexible learning opportunities. In a way, they had time and a chance to think, question, and act on the issue they chose to study. They stated that this kind of knowledge construction was not superficial but long-lasting. Masal, a Turkish teacher, stated the problem with the current educational system and what changed with HEM:

"Unfortunately, the current educational system makes students passive and decreases the retention of learning. The reason is that the curriculum is exam-bounded and does not give a chance for creativity and a free learning environment. However, thanks to HEM, I understood that doing more than listening made the difference. As a teacher, it was nice to see how much they could achieve and develop themselves with their own sources."

In addition, an ICT teacher, Ferah, explained the change in her perception of the content area and how she reflected the mindset change in her teaching:

"Everyone thinks that ICT is a content area in which students are active in the application; however, it is teacher-centered most of the time. Through HEM, I realized that we introduced the students to many applications but did not allow them to utilize these applications or knowledge in a real environment. Now, I allow my students to choose their apps and plan the lessons accordingly. I try to construct a system in which they make inquiries and work on their projects with their creativity."

HEM also resulted in changes in the perceived roles of teachers and students, which stemmed from the process-orientedness and student-centeredness of the model. Thanks to HEM, the teachers understood that actually their role should be a regulator, not a transmitter of the knowledge, and it produced better learning outcomes. Moreover, they believed that the role of the students was to think, question, and 
apply; but in traditional classrooms, the teachers did all these because of the recipient position of students. In addition, teachers gained another role during the process, a learner role with/from the students. The reason is that in HEM, students and teachers decide the problem together that they will work on. These issues differ from teachers' majors and require the inclusion of various disciplines and content areas.

Consequently, teachers need to learn about the issue during the process. In addition, teachers attend a variety of in-service training, which also changes the role of the teacher from who knows to who learns. A class teacher, Elif, states her learning process in the excerpt below:

"The students decided on working on recycling and composting. Before this, I had not had in-depth knowledge about composting. Thus, I learned a lot also from the students. Later on, I established a composting station in my class. In the summer, I explained how to do composting to people in my village. Namely, I can say that it contributed to my accumulation of knowledge."

As it is clear from the excerpt, teachers take the role of a learner and a guide in the process. This also changed the perception of teachers in that their developmental process is not finished but continues after their graduation.

Moreover, the participants asserted that HEM contributed to their becoming open to development because the model helped them realize that teaching for many years caused a disconnection from innovations in education. They all experienced burn-out and, in a way were stuck in their traditional way of teaching, although it proved to be useless or ineffective according to their observations. A class teacher can realize that he became lazy in years and closed himself to the recent developments, especially technology. In addition, Serdar, a Social Sciences teacher, expressed the change in his classroom practices, especially after a variety of in-service training:

"With HEM, I asked myself, 'Why do I behave like very traditional, old teachers? There are a lot of developments and technological tools, Web 2.0 tools, for example. In the past, I asked the students to draw maps, but it was meaningless. Now, I use an app where they can design their own maps instead of just copying. Also, I use concept maps, and I can see how effective they are in learning. HEM taught me teaching is not standard; it is more than 'just explain and go.' You should abandon your comfort zone.”

As mentioned by the participants, after HEM, the participants started to question their teaching. This questioning helped them become more open to change and developments and increased their awareness about using new teaching techniques or tools to make the class experience more effective.

Almost all of the participants mentioned the multi-disciplinary approach of the model and its contributions to participants' professional development. Both in HEM and their own classes, they used information from a variety of content areas to solve daily life problems and make their teaching more effective and versatile. Especially when they wanted to make clearer explanations or felt that the topic was too abstract for the students to understand, they supported it with other subject areas. They stated that although using this approach was not a new issue, before HEM, they had not experienced the use of this approach in a real classroom environment. HEM, in a way, was a starting point for them to design 
the lessons accordingly. A special needs teacher, Fatih, expressed how he employed this approach in his classes:

"I always thought that content areas were isolated from each other and did not think of integrating them. However, after HEM, I searched for ways of teaching Math in Physical Education lessons or Turkish in Math lessons. They have common points, and the students learn subconsciously in that way."

Another interesting example of the use of the multi-disciplinary approach came from the ICT teacher, Ferah. She stated that she experienced difficulties explaining the Scratch program because the students had to think of reflection like a mirror. After a short inquiry, she decided to use the coordinate plane in Math. With some prior knowledge of the coordinate plane, the students could easily grab the application. In addition to Ferah, Masal, the Turkish teacher, used students' mathematical knowledge of four operations. While they were working on the elements of sentences, they could not understand the double negativity and the teacher exemplified it with the rules of four operations. She said that the students had a clear understanding of the topic combined with their prior knowledge in Math. According to the participants, the change in the teachers' perspective of the use of multi-disciplines stemmed from being present with teachers from different majors at the same time in the classroom during the application of HEM. When working on the same issue, they observed that diverse points of view could be a great help to the solution of a problem. Moreover, the teachers became aware of the advantages of using various disciplines in students' learning. They asserted that HEM gave them an opportunity to experience these advantages in real contexts; however, before HEM, they only knew it theoretically.

Integration of daily life problems is one of the main foundations of the model. Daily life problems are the impetus for Harezmi students. During the whole process, they try to come up with an effective solution to a problem that they observe in their environment. This foundation of HEM enlightened the teachers about integrating daily life problems in their content areas in order to create relevant content for their students. A major criticism of a centralized curriculum was the disconnection and irrelevance of the curriculum to students' needs and context. In line with this, the participants revealed that they attempted to adapt their lesson content to students' needs or problems. Güneş, a Physical Education teacher, told her experience as follows:

"Because of the pandemic, most of my students were complaining about the weight they gained. They were at home and in front of the computer all the time due to distance education. Consequently, we planned to create a healthy food menu and would help them lose weight. In addition, I gave them appropriate exercises to make them more active and burn their calories easily."

Another class teacher, Yavuz, also mentioned the importance of touching upon these problems and the skills used to solve these problems. For example, when they were dealing with environmental problems, students worked to develop a kind of application that would help people to recycle. The teacher indicated that providing the students with opportunities to invest in some innovations contributed to 
their awareness and skills that would be helpful in the potential future problems. The following section will provide the results concerning the improvement in knowledge and skills.

\section{Improvement in Knowledge and Skills}

The second theme which emerged in the data is improvement in knowledge and skills. The participants confirmed that being involved in HEM resulted in increased knowledge and skills regarding planning, cooperation, interaction, technology, and theoretical background. These improvements were reported to stem from several characteristics of the model. The multi-disciplinary approach, in-service training, working with students and colleagues closely, reflections, and feedback from the coordinator were the main features mentioned by the participants.

Firstly, the participants pointed out that HEM contributed to their lesson planning. This planning included using a variety of sources and tools, the content of the lesson, and timing. Moreover, they understood the importance of planning and learned that planning required the application of specific rules. It was not just jotting down the activities because integrating different disciplines in the model necessitated the careful coordination of these disciplines. Through the emphasis on planning during the onset of in-service training and after working with other teachers, a Science teacher, Asl1, stated that she understood how loaded and complex she prepared the plans. She decided to abandon her perfectionist approach because perfectionism in planning did not mean perfect outcomes for both teachers and students.

The multi-disciplinary approach of the model, on the other hand, gained the participants' cooperation and collaboration skills besides better planning. They needed to be present together at the same time, do the planning together, cooperate for the paperwork and interact with each other frequently to integrate their branches into the topic. Also, they needed to cooperate with the students because the content in the model was created together with the students. Consequently, it was important to construct healthy and balanced relationships among the team members. Learning from/with other colleagues and students was another important issue raised by the participants. A Technology and Design teacher, Deniz, explained how he learned from other colleagues in the model as follows:
"It was very fun to work together. I learned a lot from my colleagues. When we conducted the classes together, I started to question my teaching critically, even the body language used by other teachers. Also, as I listened to teachers with different branches, I learned new things about different topics, and it contributed to my professional development."

Fatih, the Special Needs Education teacher, shared his experiences about learning coding with the students. While working on recycling, they aimed at developing an innovative tool; however, the teachers were not very knowledgeable about coding. The students attended coding workshops at a university, and the teachers learned from their students. In a way, the students directed the process for the tool.

As is clear from the excerpts, HEM played an important role in creating an environment in which students and teachers collaborated and cooperated to find a solution to the problem determined. Although the product was not a must in the model, they spent time together to think on the problem, its reasons, and possible solution ways; they tried to organize activities for dissemination. All these activities required the members to behave according to the rules of working in teams. These rules were 
thought to be known by the teachers already, but this might not be the case. As indicated by the Turkish teacher, Masal, the reason was that teachers were used to working alone in the classes and were very involved in their content areas. However, teachers needed to learn to collaborate with their colleagues, which would also contribute to their professional development. Also, Fatih indicated that teachers and students were considered two separate sides in the learning environment, but they had common goals, so they had to cooperate and learn from/with each other.

Constructing the lesson around the common goals and working in collaboration with students paved the way for better interaction with the students. The participants indicated that when students felt the atmosphere of a friendly and productive learning environment, they also communicated with the teachers effectively and shared their ideas freely and without the fear of being criticized or evaluated. HEM was mentioned to welcome all ideas; so, it was helpful for increased interaction with the students. Doğu, the Math teacher, expressed this environment as follows:

"Through HEM, I noticed that I became a member of this learning environment. In our daily-life practices, you are in such a hurry that you do not have a chance to be acquainted with your students; you do not know them, their characteristics, their potentials. However, when you are a member of that group, you observe them and learn about them. This interaction guides you in planning, grouping, cooperation, and finally, it makes you better as a regulator."

In addition to better interaction with the students, increased technological knowledge was confirmed by all participants in the study. All participants mentioned the contributions of the model to their technological knowledge both through in-service training and classroom applications. They understood the need to integrate technology into their daily practices and have technical knowledge that would enhance learning outcomes. Moreover, some of the students who were good at technology were said to help teachers learn new tools or systems. Teachers who had longer teaching experiences indicated that they had defamiliarized themselves with the innovative educational technologies but realized it when they were involved in the model. The comments of the ICT teacher were outstanding in terms of her gains in her technological knowledge.

"As an ICT teacher, I had known some applications or tools, but I had never had a chance to use some of them in a classroom environment. So, HEM gave me this chance to apply them. For example, instead of a very well-known presentation program, we now use Canva because it is user-friendly and functional. Moreover, I attended Ardunio training in HEM and learned more about Web 2.0 tools. I can see how effective these tools are in teaching. I developed myself professionally thanks to this model, although it is my major."

In addition to the ICT teacher, the Social Sciences teacher indicated his move towards more technologybased planning because he observed the students' improvements and thought that technology was one of the requirements of the era. On the other hand, the Science teacher said she was a bit afraid of using 
technology, but she could get rid of this feeling thanks to HEM. Both technological support from the training and multi-disciplinary approach and working with colleagues and students helped her overcome her concerns. Class teachers, as well, learned new ways to conduct the lessons through technological tools. Especially in distance education, they mentioned that these tools, including games, were very helpful to engage students in the lessons. Counselling teacher, Esma, pointed out that her attendance at Arduino training enabled her to increase her technological knowledge and address students interested in technology. The Math teacher stated that he could combine geometry and coding and discover machines' systems in daily life through the coding training he received. The Special Needs Education teacher also revealed that he did not have any profound knowledge about the technologies that could be used in education before HEM. Especially after joining various training provided by the model, he could develop himself relating to this issue. As can be understood, technological support through in-service training and a space to apply these tools and applications improved the technological knowledge of the participants and gained them the understanding that technological knowledge was a necessity in this era.

The other issue raised by the participants frequently was the theoretical background of the practices. After years of teaching, the participants mentioned that although they conducted the lessons in certain ways, they might be intuitive and lack a theoretical base. Moreover, they forgot some of their theoretical knowledge regarding their content areas or could not create a space in their classes to apply it. Consequently, they felt that the gap between the theoretical background and their classroom practices increased in time. As indicated by the participants, the model provided them with necessary theoretical information through training and support from the coordinator. The coordinators sent some recent articles, invited teachers to webinars, meetings and played the role of a bridge between the teachers and the academicians. The meetings of teachers and academicians gave the teachers a chance to see the background of the model and the academicians to evaluate the application of the model in the field. A Science teacher, Nisa, expressed her thoughts as follows:

"I was asking myself why we learned all the teaching methods that we could not use. I was really disappointed by that fact. However, in HEM, the trainer reminded us of these methods at the onset of training. Also, HEM gave me the chance to apply the methods such as thinking hats and stations. They were very abstract for me before the model."

The counseling teacher, Esma, elaborated on the issue, saying that although she did some activities or provided guidance to students, she was not aware of the reasoning, but she automatically conducted the sessions that way. HEM allowed her to understand the rationale behind the practices and support these practices theoretically.

According to the findings revealed by the participants, HEM caused changes in perceptions, beliefs, and attitudes regarding teaching. They adopted a process-oriented approach; they changed their roles as a regulator and centered the students. They welcomed the developments, and their awareness about new techniques increased together with the multi-disciplinary approach of the model. In addition, they increased their knowledge of technology and theoretical background and improved their communication and cooperation skills besides contributing to their planning. After providing the study results, the next session presents a discussion based on the literature in relation to the findings. 


\section{Discussion}

The data collected from the participants revealed important findings concerning the changes in teachers' perceptions, beliefs, attitudes, and improvements in their skills and knowledge. The current study results are in line with the previous literature in terms of teacher professional development.

HEM gives teachers opportunities to receive theoretical knowledge through in-service training both at the onset and during the process and apply this knowledge in 32-week of practice. Moreover, this process is backed up by the observations from the coordinators and reflections and the exchange of ideas in pre-and post-application meetings. The positive changes and improvements reported by the participants may be attributable to the model's being long-term, connected to teachers' contexts, and supportive. As explained by Keay and Lloyd (2011), training with these features can make coherent and long-reaching outcomes.

In addition, according to Hayes (1995), when teachers are passive recipients of the knowledge as in traditional teacher training programs, the change in teachers' behavior in terms of teaching is very limited. However, HEM differs from traditional teacher professional development programs because it is not based on the transmission of knowledge, and it is not a one-shot. The coordinators of the model organize a variety of training, and teachers can choose to attend according to their needs and the dailylife problems they select to work on. To exemplify, if the solution for the problem requires technological knowledge, the teachers have a chance to attend related training arranged a few times during the term. After the training, they use the information in the application of the model. In that sense, HEM is highly relevant and contextualized in terms of the capacity to address the needs of teachers and students. Darling-Hammond (2017) indicated that job-embedded and teachers' work-focused forms of teacher professional development programs result in permanent learning for teachers. Also, the opportunities to try new tools or techniques provided in HEM make the model experiential. If something does not work, teachers can change the technique and search for more useful choices. The construction of the model is also based on experience; both the students and teachers can re-construct their way of solution and re-design the steps of their research when they feel the necessity for it. For Darling-Hammond and McLaughlin (1995), being experiential is also an important factor that makes professional development programs successful. The experiential nature of the model is enhanced by the lack of formal assessment for both teachers and students. As the model is process-oriented, teachers may feel that their professional development is highly important, and they are not evaluated on their performance for a promotion or a raise in their salaries. The process as a whole may be considered as a personal attempt for professional development because the model does not have a top-down approach. The improvements in their skills and knowledge may result from their willingness and efforts.

Most research has pointed out the importance of collaborative work in teacher development; collaborative work has been suggested to improve teachers learning and development (LoucksHoursley et al. 1998, Nicolini et al. 2003, Hildreth and Kimble, 2004, Darling-Hammond and McLaughlin, 2011, Dolfing et al. 2021). Thanks to the multi-disciplinary approach of the model, at least 3 teachers from different branches conduct the lesson together. As the participants expressed in 
the findings, they learned from each other, gained communication skills, contributed to their knowledge about different content areas, and developed a wide horizon on the solutions of the problems. Moreover, reflections and meetings with the colleagues about the planning and activities enable them to facilitate their teaching techniques. From this perspective, the study results are compatible with the research, indicating collaborative work contributions to teachers' professional development. Basically, it has been suggested that for learning to occur, social sources and contexts which are socially and culturally constructed are needed (Vygotsky, 1978, Palinscar, 2005). Teacher learning is very similar to student learning in that teachers also learn through collaboration and sharing their experiences (DarlingHammond and McLaughlin, 2011). Follow-up support from the coordinators, which lasted through the whole process, provided guidance and a source for motivation and was reported to enhance the participants' skills and knowledge.

Moreover, the reflections and comments from the coordinator helped them internalize the effective ways regarding the application of the model. These findings are also in accordance with the previous research suggesting that for teacher professional development programs to produce long-term outcomes, ongoing support is needed for teachers (Avalos, 2011). Support is asserted to be necessary to support change (Stoll et al. 2006), especially while developing or working with new curricula (Remillard, 2005, Vos et al. 2011). In addition, when there is a lack of support, teachers may feel less confident about the innovations (Kind, 2009) or may not give well-grounded decisions (Fernandez, 2005). The support by the coordinators may have affected the participants' perspectives positively in relation to the model in the current study.

To this end, according to the present study's findings, HEM may have the potential to provide the teachers with these chances. Although all curriculum is not designed according to the model, HEM, even as an extra-curricular activity, may offer effective teacher development contexts for the teachers.

\section{Conclusion}

It is for sure that curricula in most countries put high pressures on teachers' shoulders. Their space for autonomy, roles, decisions, choices for professional development is highly limited. Most of their career or professional development plans are decided top-down and without considering teachers' preferences. HEM gives flexibility to teachers through an inquiry-based approach of the model; students and teachers decide the topic they want to work on after the observation of their environment. They do not have a pre-defined curriculum, and their plan is shaped during the process. Without formal assessment, teachers feel more comfortable and struggle for their own and students' development. Thanks to the exchange of ideas, reflections, and comments from the colleagues and the coordinators, they have a chance to adopt more useful ways and enrich their teaching techniques. Through various in-service training, they have the chance to improve their teaching practices. When given the opportunity, most teachers can change their traditional ways of teaching, opt for innovations and creativity, and transform their teaching system into a new one that can meet the needs of students, society, and era.

Regarding limitations and suggestions for future research, observation of the teachers involved in HEM may provide additional information about the changes in their perspectives, beliefs, and attitudes. These observations may give clearer and more concrete examples of the changes. Thus, the next step to elaborate on the current study may be to add observations as another data collection tool. Moreover, teachers who volunteered attended this study. These teachers might be one of those who most benefited 
from the model and had positive points of view about the model, although the change was evident in their self-reports. Nevertheless, a larger study with teachers who have doubts about the model can be deliberately called for the study. Their ideas may contribute to the development of the model in some aspects. Finally, longitudinal data on teachers' changing perspectives and practices may shed light on the model's potential for long-term effects and turning the educational system into a similar HEM curriculum. To see these effects, more research on different key players of the model and its effects should be conducted.

\section{Acknowledgments}

The researchers would like to thank the teachers who volunteered to participate in the study. Without their support, it would not have been possible to conduct this study.

\section{References}

Armour, K., 2006, Physical education teachers as career-long learners. Physical Education and Sport Pedagogy, 11(3), 203-207.

Avalos, B., 2011, Teacher professional development in teaching and teacher education Over ten years. Teaching and Teacher Education, 27(1), 10-20.

Borman, G. D., Hewes, G. M., Overman, L. T., and Brown, S., 2003, Comprehensive school reform and achievement: a meta-analysis. Review of Educational Research, 73(2), 125-230.

Creswell, J., 2003, Research design: qualitative, quantitative, and mixed methods approach (Thousand Oaks, CA: Sage).

Darling Hammond, L., and McLaughlin, M. W., 1995, Policies that support professional development in an era of reform. Phi Delta Kappan, 76(8), 597-604.

Darling Hammond, L., and McLaughlin, M. W., 2011, Policies that support professional development in an era of reform. Kappan, 92(6), 81-93.

Darling-Hammond, L., 2017, Teacher education around the world: what can we learn from international practice? European Journal of Teacher Education, 40(3), 291-309.

Dolfing, R., Prins, G. T., Bulte, A. M. W., Pilot, A., and Vermunt, J. D., 2021, Strategies to support teachers' professional development regarding sense-making in context-based science curricula. Science Education, 125, 127-165.

Fernandez, C., 2005, Lesson study: a means for elementary teachers to develop the knowledge of mathematics needed for reform-minded teaching? Mathematical Thinking and Learning, 7(4), 265-289.

Garay, I. S., and Quintana, M. G. B., 2019, 21st century skills. An analysis of theoretical Frameworks to guide educational innovation processes in Chilean context. Proceedings of the Springer International Research \& Innovation Forum, Cham, April, pp. 37-46.

Geven, K., and Santa, R., 2010, Student centred learning: survey analysis time for student centred learning. Bucharest: European Students Union. http://www.esib.org/index.php/Publications.

Girvan, C., Conneely, C., and Tangney, B., 2016, extending experiential learning in teacher professional development. Teaching and Teacher Education, 58(2016), 129-139.

Hayes, D., 1995, In-service teacher development: some basic principles. ELT Journal, 49(3), 252-261. 
Hildreth, P. M., and Kimble, C., 2004, Knowledge networks: innovation through communities of practice. (Harshey, PA; London: Idea Group).

In de Wal, J. J., den Brok, P. J., Hooijer, J. G., Martens, R. L., and van den Beemt, A., 2014, Teachers' engagement in professional learning: exploring motivational profiles. Learning and Individual Differences, 36(2014), 27-36.

Keay, J.K., and Lloyd, C.M., 2011, Linking children's learning with professional learning. (Rotterdam: Sense).

Keay, J. K., Carse, N., and Jess, M., 2019, Understanding teachers as complex professional learners, Professional Development in Education, 45(1), 125-137.

Kennedy, A., 2014, Understanding continuing professional development: the need for theory to impact on policy and practice. Professional Development in Education, 40(5), 688-697.

Kind, V., 2009, Pedagogical content knowledge in science education: perspectives and potential for progress. Studies in Science Education, 45(2), 169-204.

Loomis, S., Rodriguez, J., and Tillman, R., 2008, developing into similarity: global teacher education in the twenty-first century. European Journal of Teacher Education, 31(3), 233-245.

Loucks-Horsley, S., Hewson, P., Love, N., and Stiles, K., 1998, Designing professional development for teachers of science and mathematics. (Thousand Oaks, CA: Corwin Press).

Ministry of National Education, Date of access: 05/04/2021. http://harezmi.meb.gov.tr/assets/uploads/dokumanlar/0a721b92e7a0ea87d4f2e4f04fc01b1f.pdf

Nicolini, D., Gherardi, S., and Yanow, D., 2003, Knowing in organizations: a practice-based approach. (New York: Routledge).

Palinscar, A., 2005, Social constructivist perspectives on teaching and learning'. In: An Introduction to Vygotsky (2nd ed.), edited by H. Daniels. (Sussex: Routledge), pp. 285-315.

Remillard, J. T., 2005, Examining key concepts in research on teachers use of mathematics curricula. Review of Educational Research, 75(2), 211-246.

Scott, D. M., Smith, C. W., Chu, M.-W., and Friesen, S., 2018, Examining the efficacy of inquiry-based approaches to education. Alberta Journal of Educational Research, 64(1), 35-54.

Stake, R. E., 2005, Qualitative case studies. In: The Sage handbook of qualitative research (3rd ed.), edited by N. K. Denzin, and Y. S. Lincoln. (Thousand Oaks, CA: Sage Publications), pp. 443-466.

Stoll, L., Bolam, R., McMahon, A., Wallace, M., and Thomas, S., 2006, Professional learning communities: a review of the literature. Journal of Educational Change, 7(4), 221-258.

Vos, M. A. J., Taconis, R., Jochems, W. M. G., and Pilot, A., 2011, Classroom implementation of context-based chemistry education by teachers: the relation between experiences of teachers and the design of materials. International Journal of Science Education, 33(10), 1407-1432.

Velikova, M., 2020, The continuing professional development of teachers for schools' innovative teaching methods. Trakia Journal of Sciences, 18(1), 331-334.

Vygotsky, L., 1978, Mind in society. (Cambridge, MA: Harvard University Press). 